\title{
The Lines Between: Relational Subjectivities and the Practice of Observational Drawing
}

\author{
By Jessica Taylor (University of Roehampton)
}

My purpose here is to explore how drawing, as an alternative and non-verbal mode of being and relating, enables a new experience of intersubjectivity. I suggest that language can lock us into rigid and predefined models of relationship and may prevent versions of ourselves from coming into being. I suggest that, in a social context that privileges verbal communication, people with learning disabilities can be positioned in a discourse of representation depicting them as passive and dependent. Drawing opens a space for non-discursive subjectivities to be explored in the context of relationship. I illustrate these ideas with a vignette of my time spent in a community with adults with learning disability and communication difficulties, whilst also drawing on my experience of working for organisations that support adults with learning disability.

The women I depict in the sketches below (Figures 1 and 2), around which this text is based, are residents of a sustainable agricultural community in the North of England. ${ }^{1}$ This community includes adults with learning disability, and volunteer co-workers without learning disability and their families. In September 2010, I spent a short time in this community as a volunteer co-worker. The portraits were requested by four women with learning disability and additional special needs after having seen me making sketches of their environment. The images generated a sharing not only amongst the women, but also within the household in which I was staying. Namely, the women showed their portraits to others in the community and experienced others' reactions to them and to the sketches. In doing so, they saw these visual representations of themselves through the eyes of others.

Whilst my explicit role at the time was not that of fieldworker or therapist, my perspectives and observations during my stay were influenced by my background in anthropology and previous experience as a support worker with adults with learning disability. Since that time I have brought further experiences to reflect on these drawings. These include the use of observational drawing in my work with young people in a hospital and, more recently, my training in art psychotherapy. These experiences have provided additional frameworks that continue to inform my thoughts about the process of these particular sketches.

\footnotetext{
${ }^{1}$ The community will not be named for reasons of confidentiality.
} 

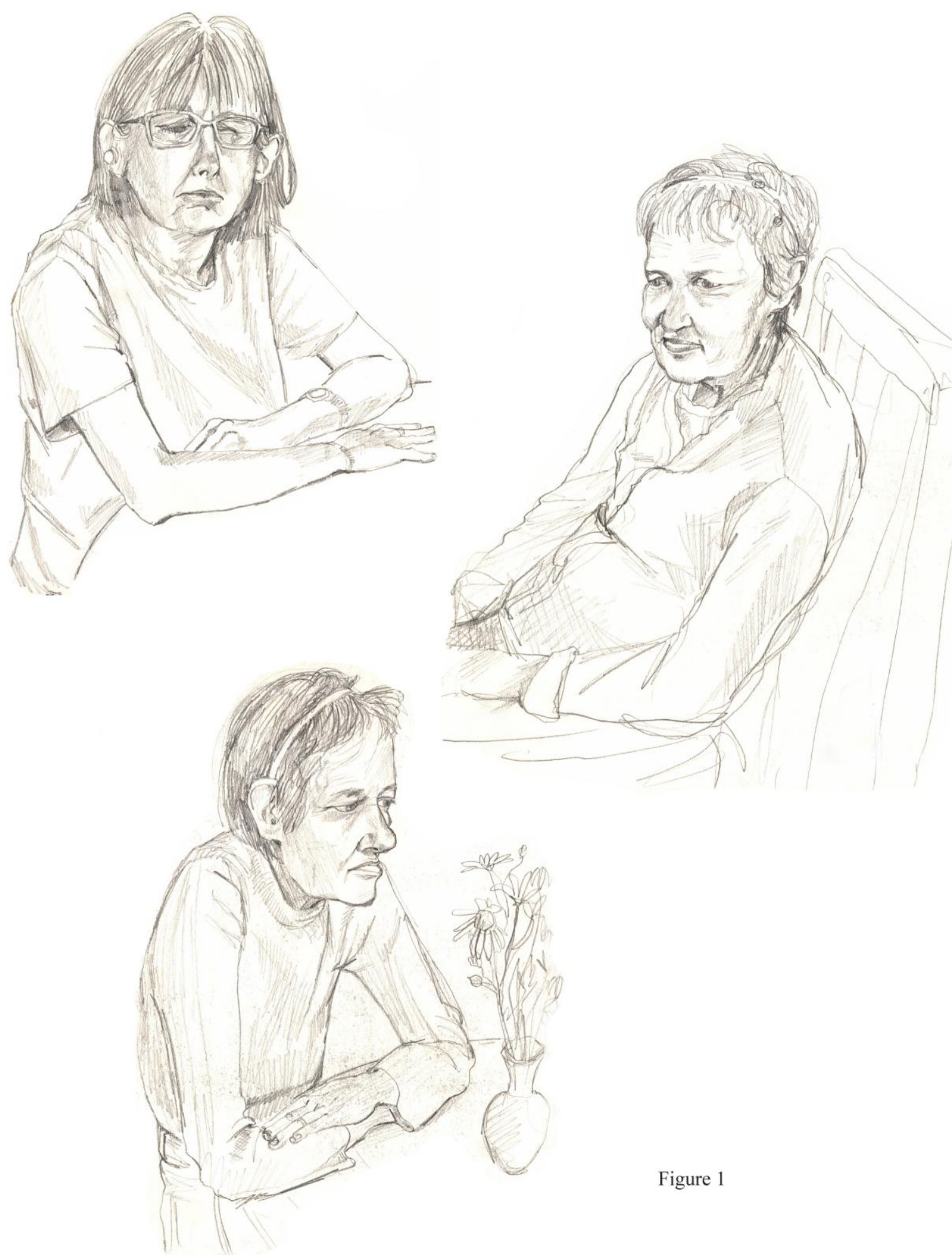

Figure 1 

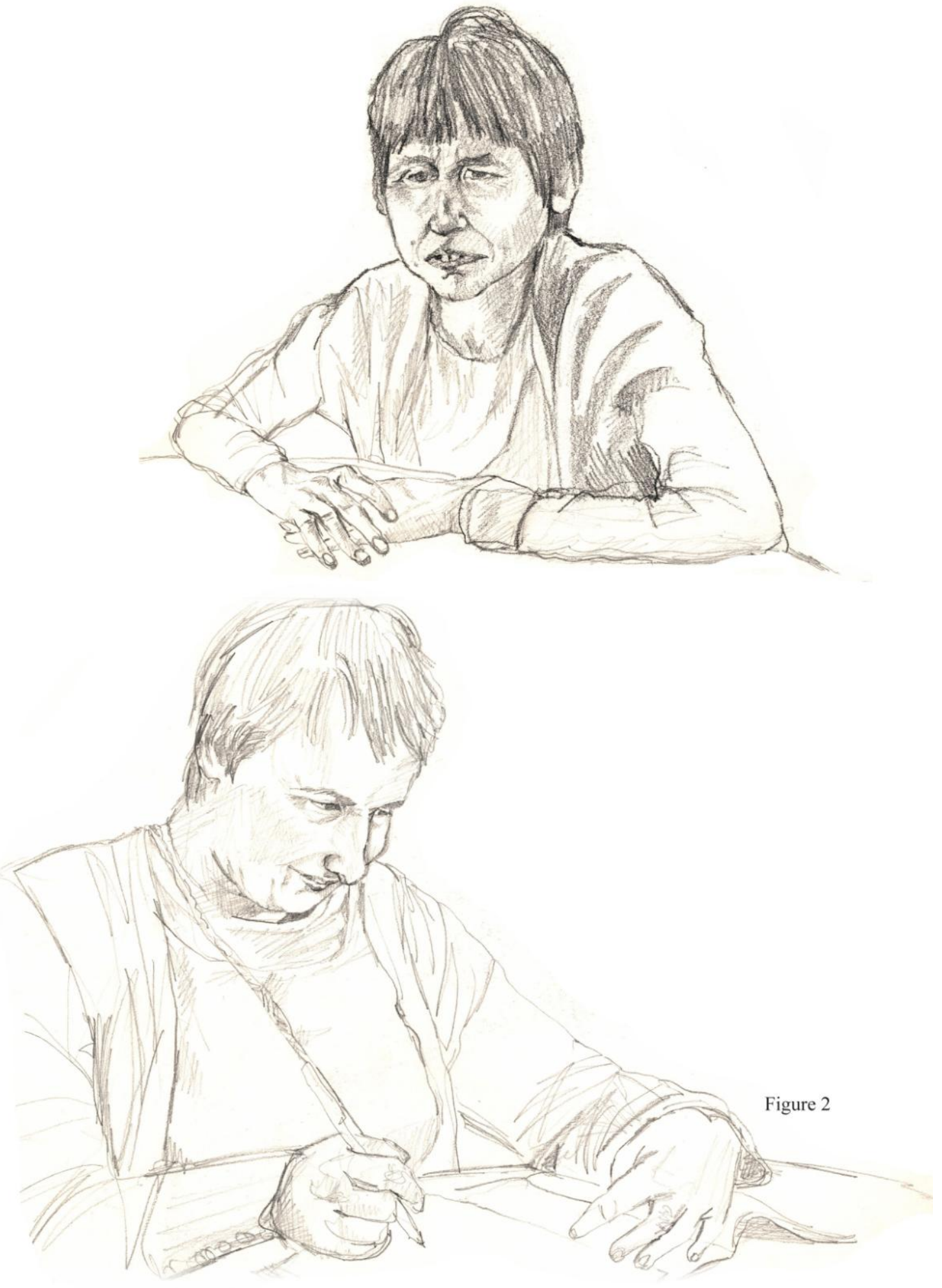
Of the three hundred or so members of the community, roughly two-thirds are people with learning disability who are living as long-term residents in the community. The community is housed in farmhouses dotted throughout a stretch of a valley. Adults with learning disability share homes, work and social lives with co-workers who support them. Volunteer co-workers from the UK and abroad generally stay for a period of months or years, participating in community life and work. Day-to-day living involves a variety of handicrafts and farm industry designed to facilitate the self-sufficiency of the community. Participation is an intrinsic part of the community ethos: an ethos that places emphasis on valuing the individual whilst acknowledging a wide array of different skills and needs, and appreciating the importance of being engaged in work that contributes to the social and practical life of the community.

In my previous work with organisations supporting adults with learning disability, I have often found that processes designed to ensure participation of people with learning disability in decision-making frequently rely on an individual's ability to communicate verbally. Yet it is precisely in the area of verbal communication that people with learning disability often have the most difficulty. For this reason, when agency is ascribed solely to verbal communication, people with learning disability may experience themselves as dependent on others' interpretations of their verbal expression and subsequently experience choices as being made for them. In this way, processes of verbal consultation aimed at increasing participation can in practice create and sustain a sense of dependency. As a consequence, people with learning disability can be fastened into a discourse of representation that depicts them as passive and dependent, often extending to a more pervasive lack of agency and engagement in making life choices.

Paradoxically, individuals' attempts to redefine this passive representation of themselves within the dominant mode of language can reinforce a representation of a dyadic relationship configured in passive/active terms. The construction of inherently unequal relationships in the context of learning disability, which are reproduced through processes of verbal participation, has previously been referred to in anthropological literature (see Blow 2008). It is interesting to note that in interactions between people with learning disability and those without, within a social context where language is prioritized, either party may be positioned in a childlike role vis-àvis the other. The resulting communication pattern can be described as conforming to a repetitive complementary 'one-up, one-down interact' (Nussbaum et al. 2000) as opposed to allowing for variation, particularly in terms of 'one-across' interacts that may signal a more equal relationship. In the daily verbal communication between myself and the members of the community with learning disability, I often felt positioned as a child in relation to them, as their verbal communication suggested that I was expected to learn tasks slowly. I was encouraged and mildly scolded in the learning process. I felt that this instructional and instrumental use of language located us within a system of adult-child interaction which felt inflexible and open only to being reversed rather than being renegotiated into a more reciprocal configuration.

This experience suggests to me that, as we navigate the world using words, we may miss the subtle ways of being and ways of 'being with' that people use to reexperience their subjectivity in relation to others. In contrast to the rather hierarchical and structured relationship shaped by verbal discourse, I was struck by the different mode of 'being with' that these women would perform daily in one another's 
company, which was often both silent and intense. I found it difficult to participate in this, but I eventually found a way to momentarily and partially experience this different mode of 'being with', through using an equally non-word-based form of communication: sketching. The process of making these sketches produced a new kind of engagement and provided the opportunity for a new interactional field to emerge, in which we were not bound by language to repetitious roles. This new interactional field was one of being in the moment and holding each other in mind. It involved an intense consciousness of self and other; a consciousness of the self within the gaze of the other.

The process of drawing and being drawn, of looking and being seen, is a multisensory and emotional process, engaging the whole body and sense of self (Pink, Hogan and Bird 2011). The physical act of making a line that occurs within the space between two people is a powerful act. The focus of interaction becomes the space between. Mutual consciousness of this process situates both people in a new relation to one another. Hyland Moon suggests that interactions anchored in creative rather than discursive language set up a 'qualitatively different kind of interaction' (2002: 116) and make possible alternative 'ways of knowing' the self and other. For me this points towards the possibility, through interdisciplinary practice and through means of communication that are not word-based, to let intersubjectivities of different qualities emerge.

Observational drawing does not fit the widely accepted paradigm of art psychotherapy, which primarily focuses on facilitating the creative expression of its participants. I am not suggesting that it should occupy a central place in the discipline. Nonetheless, I would suggest that the interplay of subject and object, of self and other, that accompanies the practice of observational drawing makes it a rich terrain for art psychotherapy to explore. In depicting the other, we necessarily project aspects of ourselves, and in this way drawing can be both revelatory and exposing of both parties. An enactment of mutual vulnerability attends the practice of observational drawing, when both are conscious and consenting to the process. It is then precisely through this non-verbal participation of the therapist that reflections on the self, as constituted intersubjectively, may be further enabled.

By offering my own subjective representations of these four women, I do not wish to take away agency from them, but rather to make visible the products of a scenario in which I felt we participated in a re-experiencing of one another. I will close with an image (Figure 3) of myself drawn by a young person I have recently been working with in a hospital environment: a re-experiencing of myself in the eyes of another. 


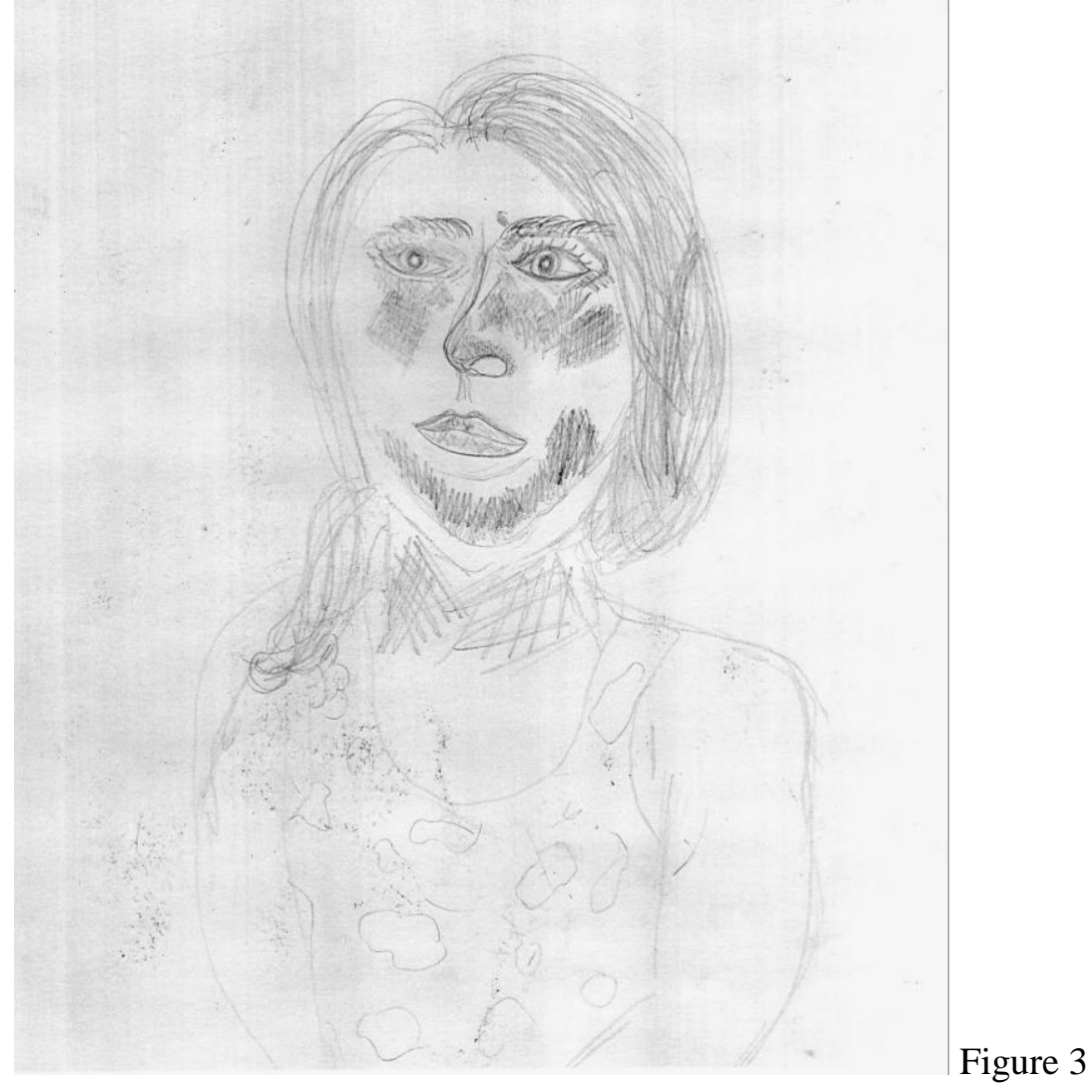

\section{About the author}

Jessica Taylor is an artist and anthropology graduate, currently training in art psychotherapy within the inpatient service of a London NHS Trust. She has five years' experience of working with adults and children with learning disabilities.

\section{Bibliography}

Blow, Beccy (2008), 'Empowering to Disempower: a Dilemma When Working with Adults with Learning Difficulties', Anthropology Matters, 10 (1). http://www.anthropologymatters.com/index.php?journal=anth_matters\&page=article, (access date 03 August 2011)

Hogan, Susan, and Sarah Pink (2010), 'Routes to Interiorities: Art Therapy and Knowing in Anthropology', Visual Anthropology, 23: 158-74.

Hyland Moon, Catherine (2002), Studio Art Therapy: Cultivating the Artist Identity in the Art Therapist, London and Philadelphia: Jessica Kingsley Publishers.

Lacan, Jacques (2001), 'The Mirror Stage as Formative of the Function of the I', in Ecrits: A Selection, London: Routledge Classics.

Nussbaum, Jon F, Loretta L. Pecchioni, James D. Robinson and Teresa L. Thompson. (2000), Communication and Aging, 2nd ed., Hillsdale, NJ: Lawrence Erlbaum Associates.

Pink, Sarah, Susan Hogan and Jamie Bird (2011), 'Intersections and Inroads: Art Therapy's Contribution to Visual Methods, International Journal of Art Therapy 16 (1): 14-19.

Winnicott, Donald (1971), Playing and Reality. London: Tavistock Publications 